\title{
Acute Chest Syndrome in A 10-Year-Old Male with Sickle Cell Disease
}

\section{Hazar Khankan*}

Pulmonology Division, Department of Pediatrics, Children's Damascus University Hospital, Syria

*Corresponding Author: Hazar Khankan, Pulmonology Division, Department of Pediatrics, Children's Damascus University Hospital, Syria.

Received: October 16, 2019; Published: October 29, 2019

\section{Case Presentation}

A 10-year-old male with known sickle cell disease was admitted to Children's Damascus University Hospital with a history of tightness, shortness of breath, severe chest pain, and back pain for 2 days.

On physical examination, he had crackles with slightly diminished breath sounds on the base of both sides of the chest. Oxygen saturation was $94 \%$ on room air. The patient was hemodynamically stable.

Investigations revealed hemoglobin of $8.4 \mathrm{mg} / \mathrm{dl}$ and total leucocyte count of $16,000 / \mathrm{mm} 3$ (Polymorphs 78\%, lymphocytes $16 \%)$. CXR showed lateral opacity in the right mid- and lower- lung field and lateral opacity in the left mid-lung field (Figure 1). Chest computed tomography images showed bilateral consolidations predominating at lung bases (Figure 2,3).

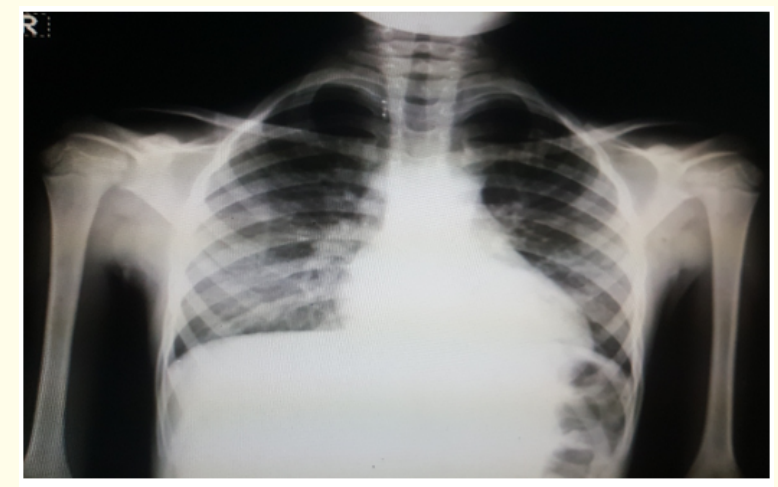

Figure 1

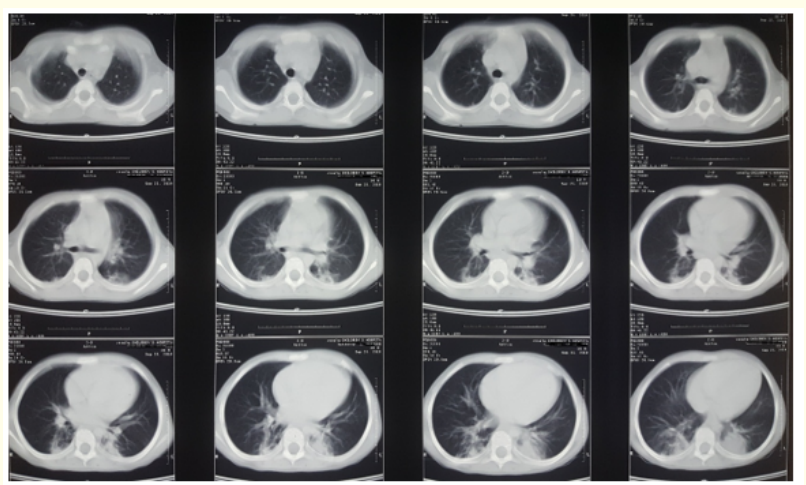

Figure 2

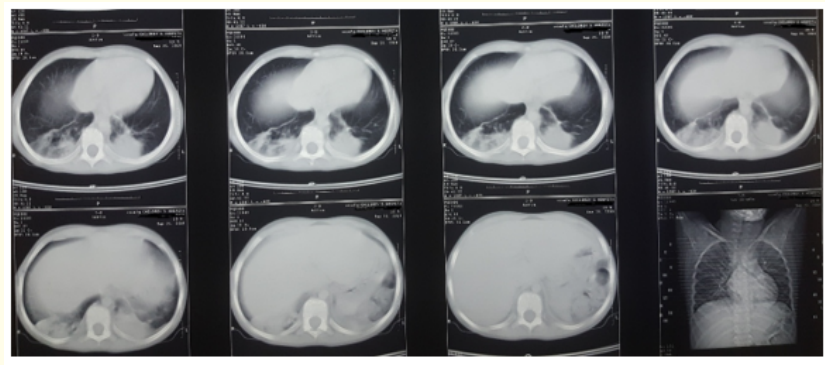

Figure 3

A diagnosis of acute chest syndrome (ACS) was made and the management included analgesics, intravenous fluids, oxygen, wide spectrum antibiotics and red blood cell transfusion.

Volume 2 Issue 11 November 2019

(C) All rights are reserved by Hazar Khankan. 